Aim The aim of this Audit was to assess if STI screening in a single Level 1 GP surgery met BASHH Guidelines.

Methods A retrospective audit of 15000 patients was carried out over an audit period of 2 years. Notes of patients coded with a positive test result for Chlamydia or Gonorrhoea were reviewed and clinical practice compared to $\mathrm{BASHH}$ guidelines in 4 areas:

- Method of investigation

- Antibiotic treatment

- Screening offered

- Partner notification.

Results

\begin{tabular}{ll}
\hline Audit standard & $\begin{array}{l}\text { Percentage of patients } \\
\text { with positive diagnosis of } \\
\text { Chlamydia/Gonorrhoea }\end{array}$ \\
\hline Gold standard investigation used for diagnosis & $62 \%$ \\
Appropriate antibiotic used & $100 \%$ \\
Screening for HIV and Syphilis performed or offered & $19 \%$ \\
Risk assessment/screening performed for Hepatitis & $4 \%$ \\
Partner notification discussed at time of treatment & $79 \%$ \\
\hline
\end{tabular}

Discussion Results would suggest that clinical practice does not always meet BASHH guideline recommendations. Also of note is the low number of diagnoses, a total of 29 in the 2 year audit period. During this time there were 7636 patient encounters of people aged 17-24, all of which are potential screening/health promotion opportunities. Missed opportunities to promote sexual health or perform a full sexual health screen could lead to a higher prevalence of unrecognised sexual health conditions in an at risk group, where extreme rurality can make access to local sexual health clinics challenging.

\section{P162 DO STAFF IN SEXUAL HEALTH FEEL COMPETENT SEEING MEN POST INTEGRATION OF SERVICES?}

${ }^{1}$ Alison Currie*, ${ }^{2}$ Susan Brechin. ${ }^{1}$ Department of Sexual Health, NHS Lanarkshire, UK; ${ }^{2}$ Department of Sexual Health, NHS Grampian, UK

\subsection{6/sextrans-2015-052126.205}

Background/introduction Integration of Genitourinary Medicine and Sexual and Reproductive Health is happening across Scotland. This means that some staff previously seeing only women are now dealing with men.

Aim(s)/objectives We wanted to identify if staff felt competent and trained to manage male patients.

Methods A link to a web based survey (10 questions) was emailed to all clinical staff in two services in Scotland who provide specialist care to a similar size of population but have a different approach to clinic service provision.

Results There were 16 responses from centre 1 and 21 responses from centre $2.68 \%$ (centre 1 ) had routinely seen male patients prior to integration versus 33\% (centre 2.) $81 \%$ (centre 1 ) and $66 \%$ (centre 2 ) said they felt comfortable taking a history and examining male patients. $100 \%$ (centre 1) but only $71 \%$ (centre 2) said they had access to local and national guidelines in the clinic. $75 \%$ (centre 1) and $62 \%$ (centre 2) felt they had enough training for managing straightforward cases in both heterosexuals and MSM. 14\% (centre 2) felt they had enough training for only heterosexual men but not enough for MSM. 25\% (centre 1) and 24\% (centre 2) felt they hadn't had enough training for managing either heterosexual males or MSM.

Discussion/conclusion The survey highlights that there is further training needed within both centres so that staff feel confident in managing both heterosexual males and MSM.

\section{P163 YOUNG ADULTS' VIEWS OF BEING OFFERED RE-TESTING FOR CHLAMYDIA AFTER A POSITIVE RESULT: RESULTS OF A 2014 ONLINE SURVEY}

${ }^{1}$ Thomas Hartney*, ${ }^{2}$ Paula Baraitser, ${ }^{1}$ Kate A Folkard, ${ }^{1}$ Kevin Dunbar, ${ }^{1}$ Anthony Nardone. ${ }^{1}$ Centre for Infectious Disease Control and Surveillance, Public Health England, London, UK; ${ }^{2}$ Sexual Health Research Group, Kings College Hospital NHS Foundation Trust, London, UK

\subsection{6/sextrans-2015-052126.206}

Background/introduction Individuals who test positive for chlamydia are at increased risk of subsequently testing positive. NCSP standards recommend offering re-testing three months after treatment completion. Concerns have been raised that retesting could undermine prevention messages.

Aim(s)/objectives To elicit young adults' views on the acceptability, and their preferred method, of being offered re-testing, as well as their reaction to and understanding of re-testing.

Methods We conducted a cross-sectional web-based anonymous survey of 1,218 young adults aged 16-24 resident in England with a history of chlamydia testing. Respondents were recruited through a market research panel, and Likert-scale questions were based on a young adult focus group.

Results The most acceptable and preferred methods of being offered re-testing were being given an appointment with initial test result (75\%, 914/1,218 acceptable; 17\%, 204/1,218 preferred) and being sent a text message reminder (72\%, 875/1,218 acceptable; 20\%, 244/1,218 preferred). Most said they would welcome an offer of re-testing $(84 \% ; 1024 / 1,218)$ and understand why they were offered this $(82 \%, 994 / 1,218)$. Most agreed that if they were offered re-testing they would be more likely to complete the course of chlamydia treatment (83\%, 1007/ $1,218)$ and use condoms with their partner until the test $(80 \%$, 970/1,218). Most disagreed that that they would be more likely to have one-night stands $(63 \%, 772 / 1,218)$ or discourage their partner to get tested $(60 \%, 735 / 1,218)$.

Discussion/conclusion Young adults report they would welcome an offer of re-testing and understand the reasons for being offered this. There was little evidence that it would increase sexual risk behaviour.

\section{P164 DOES A WALK-IN FOLLOW-UP CLINIC FOR GENITAL WARTS DECREASE CLINIC NON-ATTENDANCE RATES?}

${ }^{1}$ Helen Bradshaw*, ${ }^{2}$ Alice Bryant, ${ }^{1}$ Rachel Drayton. ${ }^{1}$ Cardiff and Vale NHS Trust, Cardiff, UK; ${ }^{2}$ Cardiff University, Cardiff, UK

\subsection{6/sextrans-2015-052126.207}

Background BASHH guidelines recommend a follow-up review in the management of some sexually transmitted infections; however, patient non-attendance for booked follow-up appointments leads to inefficiency in service provision. In 2013 we reviewed our booked follow-up appointments and found our 
non-attendance rate was 31\%. The condition with most frequent non-attendance was genital warts, at $38 \%$. In response to this, a specific walk-in warts review (WWR) clinic was introduced and its impact reviewed.

Methods A retrospective review of non-specialist doctor and nurse follow-up appointments for 2 weeks (19/5/14-1/6/14), 6 months following the establishment of the WWR clinic, compared to 2 weeks prior to its introduction $(25 / 2 / 13-10 / 3 / 13)$.

Results In total 85 patients were given a booked non-specialist follow-up appointment in the 2014 sample, compared to 103 in the 2013 sample. 19 patients attended for warts review (15 in the WWR clinic, 4 booked appointments) in the 2014 sample, compared to 12 patients who attended their booked warts review in the 2013 sample. Overall the non-attendance rate for non-specialist booked reviews was $28 \%$ in the 2014 sample, compared to $31 \%$ in the 2013 sample ( $\mathrm{p}=0.68)$. Non-attendance in the 2014 sample was most frequent for gonorrhoea test of cure, blood tests and vaccines $(21 \%, 13 \%$ and $13 \%$ of nonattendees, respectively).

Discussion Overall the non-attendance rate for follow-up appointments was not significantly lower following introduction of the WWR clinic. However convenience for patients has improved. Further work is needed to ascertain the optimal way of delivering best practice clinical care whilst ensuring efficient service provision.

\section{P165 DIFFERING TRAJECTORIES OF SEXUAL HEALTH CLINIC (SHC) ATTENDANCE IN MEN-WHO-HAVE-SEX-WITH-MEN (MSM) AND HETEROSEXUAL MEN: CAN WE USE THESE TO PLAN SERVICES?}

${ }^{1}$ Miriam Samuel, ${ }^{2}$ Martina Furegato*, ${ }^{2}$ Gwenda Hughes, ${ }^{3,4}$ Jackie Cassell, ${ }^{2}$ Hamish Mohammed. 'Guy's and St Thomas' NHS Foundation Trust, London, UK; ${ }^{2}$ Public Health England, London, UK; ${ }^{3}$ Brighton and Sussex Medical School, Brighton, UK; ${ }^{4}$ Kent Surrey and Sussex Public Health England Centre, West Sussex, UK

\subsection{6/sextrans-2015-052126.208}

Background Understanding why patients attend SHCs can inform service development.

Aims To describe SHC attendance patterns amongst heterosexual men and MSM.

Methods Heterosexual and MSM first attending SHC in 2012 were identified through the GUM Clinic Activity Dataset-v2 and followed for 365 days. Attendance frequency and outcomes were recorded. Attendance outcomes were classified: 'test-only' for negative sexually transmitted infection (STI) testing (chlamydia, gonorrhoea, syphilis, HIV) and no other service/diagnosis; 'any-STI'; 'non-STI' for other conditions; 'other-GU-service' such as health advice, post-exposure prophylaxis/vaccination; and 'Other' episodes not requiring treatment.

Results 809,106 attendances were identified among 438,609 men (81.37\% heterosexual, $12.96 \%$ MSM). The Table describes age, visit frequency and attendance outcomes. Multivariate Poisson regression adjusted for age, ethnicity, and area-level deprivation demonstrated that attendance frequency was greater amongst MSM (Incidence Rate Ratio 1.69, p < 0.001) and men with any-STI at first attendance (IRR 1.67, p < 0.001).

Discussion Men who are appropriate for clinically and cost-efficient pathways, such as telephone review and home testing, could be identified at first attendance and offered customised care pathways stratified by risk.

\begin{tabular}{lll} 
Abstract P165 Table 1 & Men attending sexual health clinics \\
\hline & \multicolumn{1}{l}{ Heterosexual } & MSM \\
& $\%$ & $\%$ \\
\hline Age at first attendance & & \\
$\quad \leq 15$ & 0.48 & 0.18 \\
$16-19$ & 10.01 & 5.13 \\
$20-24$ & 26.37 & 18.06 \\
$25-34$ & 35.87 & 35.01 \\
$35-44$ & 15.37 & 22.14 \\
$45-64$ & 10.80 & 17.73 \\
$\geq 65$ & 1.09 & 1.75 \\
No. of attendance in 365 days & & \\
1 & 65.66 & 39.71 \\
2 & 19.88 & 19.89 \\
3 & 7.03 & 13.25 \\
4 & 3.20 & 8.97 \\
$\geq 5$ & 4.22 & 18.18 \\
Visit frequency, median (IQR) & $1(1-2)$ & $2(1-4)$ \\
Attendance outcomes & & 21.29 \\
Test-only & 41.44 & 13.88 \\
Any-STI & 22.17 & 1.77 \\
Non-STI & 3.41 & 19.99 \\
Other-GU-service & 6.70 & 49.23 \\
Other & 31.93 &
\end{tabular}

\section{P166 "IF YOU BUILD IT, THEY WILL COME": HOW THE TARGETED LOCATION OF A SEXUAL HEALTH CLINIC WITHIN THE SOCIAL HEART OF AN AT RISK COMMUNITY CAN SIGNIFICANTLY INCREASE THE DETECTION AND MANAGEMENT OF INFECTIONS}

Elizabeth Kershaw*. Chelsea and Westminster Hospital NHS Foundation Trust, 56 Dean Street, London, UK

\subsection{6/sextrans-2015-052126.209}

Background/introduction A 2009 decision to relocate a sexual health and HIV clinic to an area with the highest density of gay venues in Europe was based on the belief that positioning a service directly where a high risk and vulnerable population socialised would facilitate regular sexual health screening for men who have sex with men (MSM), improve the early detection of HIV and other infections, and reduce onward transmission.

Aim(s)/objectives This study examined whether the relocation had led to the anticipated increase in overall attendances and pathology specifically in MSM beyond the increase in national STI rates reported by Public Health England. As the relocation effect cannot be directly measured, any significant discrepancy between the two rates could be used as a proxy for success.

Methods Attendances and infection rates for 2008 at the former clinic were compared with those for 2013 at the new clinic (from KC60 codes). The overall infection increase was then compared with the increase in STI rates reported nationally by Public Health England between 2008 and 2013. The specific proportion of infections in MSM was compared with the national data for 2013.

Results Attendances increased by 22\% from 56,181 to 68,395, with $61 \%$ of patients in 2013 reported as homosexual. The increase in infections significantly exceeded both this and rates reported by PHE, with $84 \%$ of infections reported in MSM. 